\title{
Densification of Wood-Influence on Mechanical and Chemical Properties when 11 Naturally Occurring Substances in Wood Are Mixed with Beech and Pine
}

\author{
Stefan Frodeson ${ }^{1, *(\mathbb{D})}$, Anthony Ike Anukam ${ }^{1}{ }^{(\mathbb{D}}$, Jonas Berghel ${ }^{1}\left(\mathbb{D}\right.$, Magnus Ståhl $^{1}$, \\ Rasika Lasanthi Kudahettige Nilsson ${ }^{1}$, Gunnar Henriksson ${ }^{2}$ and Elizabeth Bosede Aladejana ${ }^{3}$ (D)
}

\section{check for}

updates

Citation: Frodeson, S.; Anukam, A.I.; Berghel, J.; Ståhl, M.; Lasanthi Kudahettige Nilsson, R.; Henriksson, G.; Bosede Aladejana, E. Densification of Wood-Influence on Mechanical and Chemical Properties when 11 Naturally Occurring Substances in Wood Are Mixed with Beech and Pine. Energies 2021, 14, 5895. https://doi.org/10.3390/en14185895

Academic Editor: Mejdi Jeguirim

Received: 10 August 2021

Accepted: 13 September 2021

Published: 17 September 2021

Publisher's Note: MDPI stays neutral with regard to jurisdictional claims in published maps and institutional affiliations.

Copyright: (c) 2021 by the authors. Licensee MDPI, Basel, Switzerland. This article is an open access article distributed under the terms and conditions of the Creative Commons Attribution (CC BY) license (https:// creativecommons.org/licenses/by/ $4.0 /)$.
1 Environmental and Energy Systems, Department of Engineering and Chemical Science, Karlstad University, SE-651 88 Karlstad, Sweden; anthonyanukam16@gmail.com (A.I.A.); jonas.berghel@kau.se (J.B.); magnus.stahl@kau.se (M.S.); lasanthi123@yahoo.com (R.L.K.N.)

2 Division of Wood Chemistry and Pulp Technology, Department of Fiber and Polymer Technology, Royal Institute of Technology, KTH, SE-100 44 Stockholm, Sweden; ghenrik@kth.se

3 Electron Microscopy Unit, Central Analytical Laboratory, Faculty of Science and Agriculture, University of Fort Hare, Alice 5700, South Africa; ealadejana@ufh.ac.za

* Correspondence: Stefan.Frodeson@kau.se; Tel.: +46-54-700-2081

\begin{abstract}
The need to increase the use of renewable biomasses for energy supply, such as fuel pellets is significant. However, different types of biomasses have different mechanical properties to be pelletized, which entails a limitation in available raw materials for pellet producers. Within this study eleven different pure substances from biomasses were separately mixed with European beech and Scots pine, to identify its impact on the densification process. Beech and pine pellets were used as control materials against their corresponding pellets mixed with substances representing: cellulose, hemicelluloses, other polysaccharides, lignin, protein, and extractives. The mechanical properties were investigated as well as FT-IR and SEM analyses on the pellets. The results showed that the addition of the substances xylan and galactan created the hardest pellets for both pine and beech and that adding extractives to wood affects pine more than beech in relation to hardness. The FT-IR data could not provide clear explanations as to the variation in hardness and springback behavior through the identification of major functional groups in each pellet. It can be concluded that biomass residues rich in xylan and galactan increase pellet quality in terms of strength and durability without affecting the production process.
\end{abstract}

Keywords: pellets; single pellet press; chemical composition; pelletization

\section{Introduction}

The need for a reduction in the use of fossil resources and an increase in the utilization of all kinds of biomasses is clear [1]. However, biomasses can be difficult to handle for logistical reasons and their transportation is also associated with high costs. This is because, at their origin, biomasses have a low bulk density (weight per unit volume), molds and other microbes can grow on humid biomasses, and non-uniform sizes of biomass particles present logistical challenges. Biomass, such as sawdust, might present problems with dust formation, which may lead to explosions. As dried pellet products, biomasses can be transported in a more energy-efficient way, as they become both homogenous in size and resistant to molds, with an increase in density [2], and the aforesaid problem related to dust formation can be effectively minimized.

The demand for biomass pellets is increasing [3], and as the pellet market grows in size, the need for raw materials also becomes greater. At the dawn of the pellet-industry era, the raw material in vogue was mostly shavings. However, to date, more roundwood also finds use as starting material for pellets [4]. The demand for roundwood can be explained 
by the industry's need to procure vast quantities of raw material, and the pelletization process calling for either a specific type of wood or a specific mixture of wood species.

The pellets are produced within the pelletizer by ground material being pressed through $6-8 \mathrm{~mm}$ channels in a die, which creates cylindrical pellets. There is a combination of factors related to the feedstock, pre- and posttreatment conditions, and the performance of the pelletizing equipment, which produces pellets with different strengths and durabilities [5,6]. Under the right conditions, strong bonds are created between particles in the pellets; the exact nature of these is not known [5,7-16]. This paucity of knowledge causes pellet producers to strive for a feedstock with a chemical composition that is as uniform as possible. This also prevents the possibility of varying the use of different types of biomaterials as raw materials. If pellet producers can handle larger variations in raw material flows, opportunities to bring onstream more wastes and byproducts will present themselves, and seasonal residues will find a new application.

One way to increase the quantity and augment the quality of pellets is to use an additive in the production process. Using additives in fuel pellet production is quite common globally, and several different additives have been tested in order to investigate how they affect different pellet parameters and the power consumption of the pelletizer [17-20]. One of the most common additives used in conjunction with densification is starch; however, there is still a paucity of knowledge regarding how starch affects the densification process and its correlation to moisture $[17,21,22]$. It is also not clear if starch only acts as a binder or if it also strengthens the effect of the bound starch already present in the chemical composition of the biomass used. Accordingly, if more knowledge about the naturally-occurring substances within the biomass and their relation to additives were to emerge, more possibilities to use new raw materials and suitable additives for pelletizing can be unearthed.

The naturally-occurring substances within biomasses, whether they are lignocellulosic or herbaceous, can generally be divided into five primary components: cellulose, hemicellulose, lignin, extractives/volatiles, and ash, while the hemicelluloses can be categorized as xylan, mannan, and sometimes galactan [23]. Frodeson et al. $(2018 ; 2019)$ studied the impact of these primary components and found that there is a difference between how different substances derived from biomasses behave during densification [23-25]. In particular, the effects of hemicelluloses on pelletizing properties are still unknown, which could explain the difference between pelletizing hard and soft wood [26,27]. Further, Larson et al. (2020) found that the hemicelluloses mannan and xylan were important predictors for target moisture content in a feedstock [27] when they tested the model and predicted the pelletizing properties based on the chemical composition of the biomass. However, biomass is composed not merely of hemicelluloses and to be able to predict pelletizing properties based on chemical composition, more knowledge within this field is needed [26,27].

So, the naturally-occurring substances in biomasses play different roles during densification, such as creating strong bonds between particles and interacting with water. If the specific characteristics and roles of these substances correlated to pelletizing could be clarified, it would be easier to mix, vary, and blend different types of biomasses based on their chemical composition. By doing so, the raw material base for pellet production can be widened. The purpose of this study is to gain an understanding of how the naturallyoccurring substances in biomasses affect pelletizing properties. The aim was to investigate and present how compression work and backpressure are affected when pure substances of naturally-occurring substances were added to woods. The effect on pellet length and hardness was investigated, and bonding properties when eleven different naturally-occurring substances in biomasses-cellulose, hemicelluloses, other polysaccharides, lignin, protein, and extractives-were tested with beech and pine. 


\section{Materials and Methods}

\subsection{Materials}

Two wood species were used as raw materials: European beech (Fagus sylvatica) and Scots pine (Pinus sylvestris). In general, the chemical compositions for these woods can be expressed as carbohydrates $72.7 \%$, lignin $24.8 \%$, extractives $1.2 \%$, and residuals $1.3 \%$ for beech, and carbohydrates $68.5 \%$, lignin $27.7 \%$, extractives $3.5 \%$, and residuals $0.3 \%$ for pine [28]. The composition of the carbohydrates within the woods used in this study was analyzed with the SCAN-CM 71 and IC methods and are presented in Table 1.

Table 1. The variation of carbohydrates within the woods in use.

\begin{tabular}{cccccc}
\hline & \multicolumn{5}{c}{ The Variation of Carbohydrates in the Woods (rel.\%) } \\
\hline & Glucose & Xylose & Mannose & Arabinose & Galactose \\
\hline Beech & 67.7 & 27.9 & 1.9 & 0.8 & 1.7 \\
\hline Pine & 66.4 & 11.4 & 16.1 & 3.0 & 3.1 \\
\hline
\end{tabular}

The methodology behind the material treatment is based on earlier studies; first, the beech and pine woods were sawn (Bosch GCM 8 SJL; Stuttgart, Germany) and the sawdust was collected within a small cyclone mounted in front of the sawdust collector. The sawdust was dried for $48 \mathrm{~h}$ at $50{ }^{\circ} \mathrm{C}$ to reach an equal dried starting point before the moisture content was measured on all materials according to SS-EN_ISO_18134-1_2015 on a wet basis $(\mathrm{wb})$, with the deviation of the amount of material below $100 \mathrm{~g}$. All materials were then ground in a Culatti Micro Hammer Mill (DFH 48; Limmatstrasse, Zurich, Switzerland) with a sieve size of $2 \mathrm{~mm}$ to attain uniform particle sizes before the materials were sieved with a sieve size of $0.350 \mathrm{~mm}$ to ensure that they appeared in powder form $[25,29]$.

The beech and pine were separately mixed with the substances at an amount of $10 \%$ of weight on a dry basis (db). Eleven naturally-occurring substances in lignocellulosic biomasses were used, which together with the control tests (pure wood) gave 24 different tests. The substances that are presented in Table 2 are categorized as polysaccharides, lignin, protein, and extractives. All the substances are equivalent materials commonly used in research studies to reflect their properties in biomasses [23-26,30-32].

Table 2. The substances that were added to beech and pine by name and their origin.

\begin{tabular}{|c|c|c|}
\hline Test & Name & Origin \\
\hline Cellulose & Avicel & $\begin{array}{l}\text { Sigma-Aldrich (Darmstadt, Germany), } \text { Avicel }^{\circledR} \mathrm{PH}-101 \\
\text { product number } 11365\end{array}$ \\
\hline Mannan & Locust bean gum mannan & Sigma-Aldrich, product number G0753 \\
\hline Xylan & Eucalypt xylan & Delivered by KTH Royal Institute of Technology \\
\hline Galactan & Latch arabinogalactan & Hunan Kangshou Pharmaceutical Co., Ltd. (Changsha, China) \\
\hline Starch wheat & Wheat starch & Native wheat starch from Solam GmbH (Kristianstad, Sweden) \\
\hline Starch potato & Potato starch & Native potato starch from Solam GmbH (Kristianstad, Sweden) \\
\hline Pectin & Apple pectin & Sigma-Aldrich, product number 93854 \\
\hline Lignin & Lignoboost lignin & $\begin{array}{l}\text { Dry Kraft lignin from the LignoBoost process } \\
\text { (Metso, Kristinehamn, Sweden) }\end{array}$ \\
\hline Protein & Protein (Soy) & Sigma-Aldrich, product number S1674 \\
\hline Tannin & Tannin & Sigma-Aldrich, product number W304204 \\
\hline Resin & Resin & $\begin{array}{c}\text { Claessons Trätjära (wood tar) AB (Gothenburg), Sweden, } \\
\text { product number } 1211000\end{array}$ \\
\hline
\end{tabular}


The moisture content in all 24 tests was aimed to be $10 \%(\mathrm{wb})$. The hydrating process has been described in an earlier study [25]. The moisture content during the tests was measured in the test samples in conjunction with compression, as well as in the pellets one week after production.

\subsection{Densification, Measurements, and Quality Tests}

Pellets were produced in a single pellet unit (SPP), described in [23,24,29], located at the Environmental and Energy Systems at Karlstad University, Sweden. The SPP holediameter and all operating parameters for the test procedure were the same as in [24] with the deviation that no nylon plugs were used.

During densification, the force, piston speed, length of pellet, and time were logged three times per second. At least ten pellets were produced in each test series, and the data have been presented as an average value with standard deviation. The study evaluated compression work and the maximum friction force and the methology for these two calculations follows [24], with the deviation that the compression work was based on the distance needed to increase the force from 0.2 to $14 \mathrm{kN}$. The compression work is depicted as $W_{\text {comp }}(\mathrm{J} / \mathrm{g})$, and the maximum friction force is depicted as $F_{\max }(\mathrm{kN}) . F_{\max }$ represents the maximal potential backpressure. The methology behind springback effect follows [25] and was measured through variations in both axial length and diameter together with density measurements. The lengths of the pellets during compression were measured when the force reached a predetermined value after a holding time and are referred to as "comp pellets", i.e., compressed pellets. The produced pellets were analyzed by measuring their weight, length, and diameter using a digital caliper directly after compression, which are referred to as "green pellets", and after one week, which are referred to as "cured pellets", following previous studies $[25,33,34]$. The solid density $\left(\mathrm{g} / \mathrm{cm}^{3}\right)$ of the pellets was analyzed as comp, green, and cured pellet. The pellet hardness $(\mathrm{kg})$ was measured using a KAHL motor-driven hardness tester (K3175-0011; KAHL, Reinbek, Germany) on cured pellets. All the hardness tests were presented as the average value based on six pellets with standard deviation.

\subsection{Fourier Transform Infrared Spectroscopic (FT-IR) and Scanning Electron Microscopic Analysis}

Based on earlier studies [29,30,35], Fourier Transform Infrared (FT-IR) spectroscopic analysis (FT-IR) was used to study structural changes through the identification of major functional groups associated with the primary components of the pellet samples, as well as to establish the role of these groups in springback behavior, in bonding, and for pellet quality in terms of hardness. FTIR spectra were obtained using an Agilent Cary 630 FTIR spectrophotometer (USA) equipped with the diamond ATR. Spectra were processed using the MicroLab PC and Resolutions Pro software. Samples of pellets from the beech and pine controls, and from mixed samples with eleven different substances added (Table 2), were analyzed at wavenumbers ranging from 650 to $4000 \mathrm{~cm}^{-1}$ at room temperature.

Scanning Electron Microscopic (SEM) analysis was conducted to determine morphological features that are relevant to the springback effect, bonding, and pellet quality in terms of hardness. The method for morphological characterization of the pellets was based on earlier study and was conducted with a JEOL (JSM-6390LV) model SEM instrument fitted with an EDX analyzer that was used for the analysis of major elemental components. The method for sample treatment can be found in [29]. Multiple images of each pellet sample were generated upon morphological analysis and a single image was selected for each sample.

\section{Results and Discussion}

This section first presents the material data (Section 3.1), followed by quality data in the form of hardness and springback effects (Section 3.2), and finally the chemical analyses in the form of FT-IR and SEM (Section 3.3). 


\subsection{Material Data}

In total, 24 different test studies were conducted: twelve each for beech and pine, where the controls represent pure beech and pine, respectively. The following tests were conducted by adding $10 \%$ of different substances (data in Table 2) $(\mathrm{db})$. The moisture content of the samples ( $1 \mathrm{~g}$ of test material used in the SPP) within this study aimed to be $10 \%(\mathrm{wb})$, but as shown in the sample column, the inlet moisture content had a variation of $10+/-1.85$. The moisture content of the produced cured pellets varied from 7.23 to $10.24 \%$ $(\mathrm{wb})$. The mass of the produced pellet (green) was nearly $1 \mathrm{~g}$, ranging from $0.962 \pm 0.019$ to $0.986 \pm 0.004$. The measured diameter of the pellets produced shows that the diameter increases slightly for most pellet tests when the pellets have been stored for a week (see the difference between green and cured pellets in Table 3). The difference in length between comp, green, and cured pellets is discussed below in relation to springback effects.

Table 3. Sample moisture content and springback data for beech and pine pellets without substances (control) and with a $10 \%$ admixture of eleven different substances.

\begin{tabular}{|c|c|c|c|c|c|c|c|c|c|}
\hline & \multirow{3}{*}{ Test } & \multirow{2}{*}{\multicolumn{2}{|c|}{ Moisture Content (\%) }} & \multicolumn{6}{|c|}{ Pellet } \\
\hline & & & & \multirow{2}{*}{$\begin{array}{l}\text { Weight (g) } \\
\text { Green }\end{array}$} & \multicolumn{2}{|c|}{ Diameter (mm) } & \multicolumn{3}{|c|}{ Length (mm) } \\
\hline & & Inlet & Pellets & & Green & Cured & Comp & Green & Cured \\
\hline \multirow{12}{*}{ 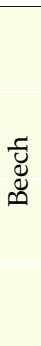 } & Control & 9.60 & 7.73 & $0.982 \pm 0.003$ & $8.23 \pm 0.012$ & $8.23 \pm 0.016$ & $12.71 \pm 0.13$ & $15.62 \pm 0.58$ * & $15.62 \pm 0.58$ * \\
\hline & Cellulose & 8.95 & 7.80 & $0.983 \pm 0.003$ & $8.21 \pm 0.006$ & $8.24 \pm 0.005$ & $11.98 \pm 0.12$ & $15.44 \pm 0.11$ & $15.37 \pm 0.12$ \\
\hline & Mannan & 9.35 & 7.85 & $0.979 \pm 0.004$ & $8.22 \pm 0.012$ & $8.24 \pm 0.008$ & $11.84 \pm 0.14$ & $15.48 \pm 0.07$ & $15.38 \pm 0.07$ \\
\hline & Xylan & 8.85 & 8.07 & $0.980 \pm 0.002$ & $8.24 \pm 0.006$ & $8.22 \pm 0.005$ & $11.66 \pm 0.10$ & $15.21 \pm 0.12$ & $14.71 \pm 0.09$ \\
\hline & Starch (w) & 10.65 & 9.10 & $0.977 \pm 0.006$ & $8.20 \pm 0.011$ & $8.21 \pm 0.000$ & $11.88 \pm 0.12$ & $15.81 \pm 0.06$ & $15.70 \pm 0.06$ \\
\hline & Starch (p) & 9.60 & $2.70 *$ & $0.980 \pm 0.005$ & $8.18 \pm 0.009$ & $8.19 \pm 0.004$ & $11.89 \pm 0.12$ & $15.21 \pm 0.13$ & $15.14 \pm 0.14$ \\
\hline & Galactan & 8.35 & 7.23 & $0.981 \pm 0.004$ & $8.30 \pm 0.015$ & $8.30 \pm 0.003$ & $11.58 \pm 0.09$ & $16.13 \pm 0.09$ & $15.94 \pm 0.11$ \\
\hline & Pectin & 11.95 & 10.24 & $0.979 \pm 0.009$ & $8.21 \pm 0.009$ & $8.22 \pm 0.010$ & $12.37 \pm 0.17$ & $16.71 \pm 0.25$ & $16.57 \pm 0.22$ \\
\hline & Lignin & 8.80 & 7.48 & $0.976 \pm 0.006$ & $8.24 \pm 0.008$ & $8.24 \pm 0.008$ & $12.68 \pm 0.06$ & $15.35 \pm 0.16$ & $15.27 \pm 0.13$ \\
\hline & Protein & 9.25 & 8.00 & $0.979 \pm 0.004$ & $8.25 \pm 0.024$ & $8.30 \pm 0.007$ & $11.88 \pm 0.11$ & $16.67 \pm 0.09$ & $16.73 \pm 0.08$ \\
\hline & Tannin & 9.55 & 8.09 & $0.974 \pm 0.011$ & $8.22 \pm 0.019$ & $8.22 \pm 0.004$ & $12.40 \pm 0.18$ & $14.75 \pm 0.27$ & $14.81 \pm 0.21$ \\
\hline & Resin & 8.51 & 8.35 & $0.979 \pm 0.005$ & $8.25 \pm 0.014$ & $8.27 \pm 0.005$ & $12.83 \pm 0.07$ & $16.40 \pm 0.15$ & $15.99 \pm 0.17$ \\
\hline \multirow{12}{*}{$\underbrace{\Xi}_{\Xi}$} & Control & 9.85 & $2.74 *$ & $0.973 \pm 0.008$ & $8.23 \pm 0.013$ & $8.18 \pm 0.008$ & $12.36 \pm 0.11$ & $16.09 \pm 0.04$ & $15.92 \pm 0.07$ \\
\hline & Cellulose & 9.65 & 7.64 & $0.980 \pm 0.003$ & $8.20 \pm 0.008$ & $8.22 \pm 0.005$ & $11.90 \pm 0.04$ & $15.78 \pm 0.04$ & $15.62 \pm 0.08$ \\
\hline & Mannan & 11.85 & 9.36 & $0.978 \pm 0.004$ & $8.20 \pm 0.019$ & $8.25 \pm 0.006$ & $11.89 \pm 0.10$ & $16.92 \pm 0.09$ & $16.80 \pm 0.06$ \\
\hline & Xylan & 9.45 & 7.96 & $0.984 \pm 0.003$ & $8.22 \pm 0.015$ & $8.24 \pm 0.006$ & $11.85 \pm 0.10$ & $15.22 \pm 0.11$ & $15.20 \pm 0.13$ \\
\hline & Starch (w) & 10.35 & 9.02 & $0.973 \pm 0.007$ & $8.23 \pm 0.005$ & $8.20 \pm 0.007$ & $12.15 \pm 0.09$ & $15.22 \pm 0.11$ & $15.20 \pm 0.13$ \\
\hline & Starch (p) & 9.50 & 8.53 & $0.971 \pm 0.012$ & $8.23 \pm 0.005$ & $8.20 \pm 0.007$ & $11.73 \pm 0.39$ & $15.47 \pm 0.24$ & $15.20 \pm 0.13$ \\
\hline & Galactan & 9.44 & 7.47 & $0.985 \pm 0.006$ & $8.24 \pm 0.009$ & $8.27 \pm 0.005$ & $12.47 \pm 0.08$ & $16.05 \pm 0.22$ & $16.39 \pm 0.12$ \\
\hline & Pectin & 10.05 & 8.64 & $0.986 \pm 0.004$ & $8.20 \pm 0.009$ & $8.22 \pm 0.005$ & $11.92 \pm 0.06$ & $16.04 \pm 0.12$ & $15.87 \pm 0.14$ \\
\hline & Lignin & 9.70 & 8.11 & $0.979 \pm 0.003$ & $8.23 \pm 0.003$ & $8.25 \pm 0.005$ & $12.13 \pm 0.08$ & $15.68 \pm 0.04$ & $15.53 \pm 0.04$ \\
\hline & Protein & 10.15 & 8.81 & $0.968 \pm 0.010$ & $8.32 \pm 0.007$ & $8.30 \pm 0.005$ & $11.60 \pm 0.15$ & $16.13 \pm 0.25$ & $16.03 \pm 0.29$ \\
\hline & Tannin & 9.65 & 8.61 & $0.973 \pm 0.018$ & $8.25 \pm 0.020$ & $8.22 \pm 0.010$ & $11.73 \pm 0.14$ & $15.19 \pm 0.33$ & $15.01 \pm 0.34$ \\
\hline & Resin & 9.90 & 8.54 & $0.962 \pm 0.019$ & $8.31 \pm 0.015$ & $8.29 \pm 0.014$ & $11.76 \pm 0.27$ & $16.34 \pm 0.45$ & $16.11 \pm 0.43$ \\
\hline
\end{tabular}

* An error measurement seems to have taken place regarding pure beech control in the length measurements between green and cured pellets and for moisture content of beech potato starch and pine control pellets.

Figure 1a reveals, that the compression work was generally higher for beech than for pine, regardless of whether substances are added. The fact that hardwood, such as beech, generates more friction, and needs a shorter press length compared to softwood, such as pine, is well known within the industry. According to Figure 1a, it is also clear that the energy utilised during compression was higher for beech. In Figure 1b, the change in compression work is presented as a percent of change vis-à-vis the control samples of pure beech and pine. An explanation for the lower compression work for pine could be the amount of extractives, or the high amount of resin, which is higher in pine than in beech. As shown in Figure 1b, the resin was one of the substances that decreased the energy requirement for compression. Another explanation could be the difference in the hemicellulose-content between pine and beech. As presented in Table 1, the main hemicellulosic substances in the beech were the xyloses, which are the building blocks of the xylan polysaccharide, while mannoses dominated in pine, as the units which form the polysaccharide mannan. As shown in Figure 1b, xylan increased the energy need for compression while mannan decreased it. The fact that the variation in the hemicelluloses, mannan, and xylan, had differences when it came to pelletization has also been shown in other studies [23-25,27]. 

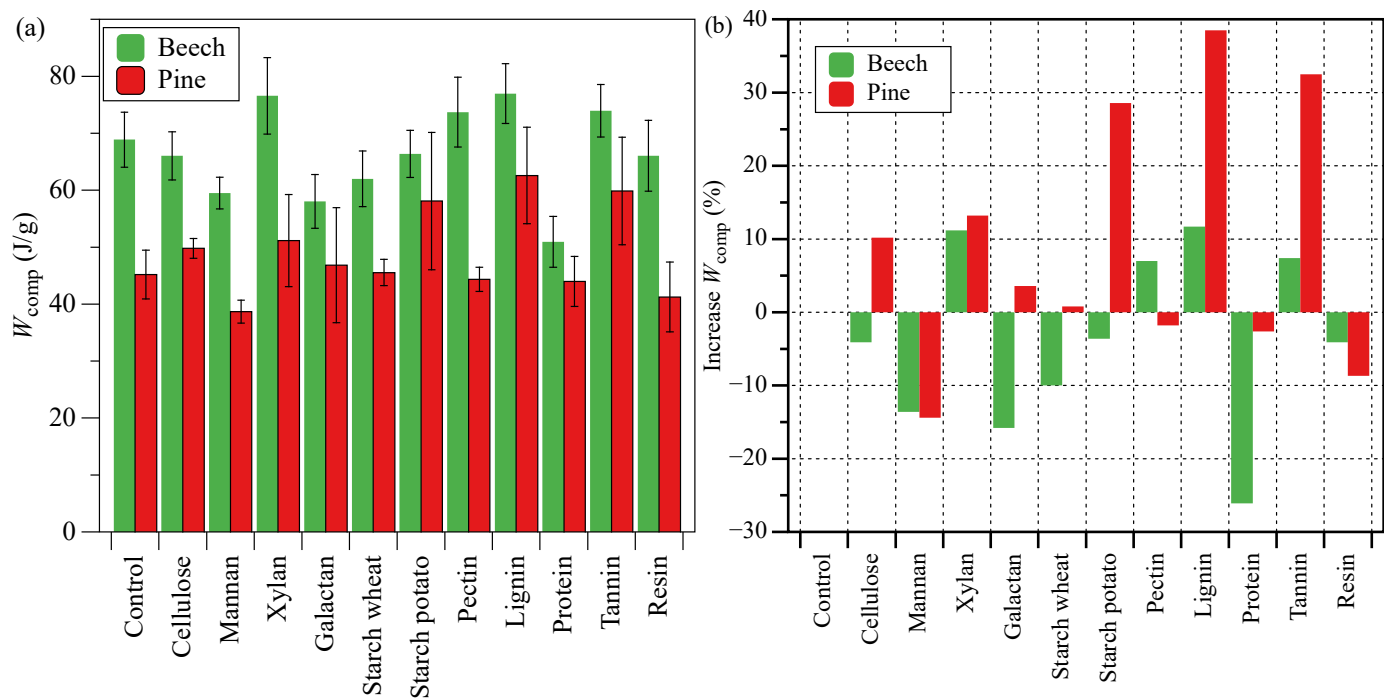

Figure 1. (a) Compression work $\left(W_{\text {comp }}\right)$ for all samples $(\mathrm{J} / \mathrm{g})$ and $(\mathbf{b})$ change of $W_{\text {comp }}$ compared to pure beech and pine $[\%(w b)]$.

Another result that stood out was the increase in compression work when potato starch, lignin, and tannins were added to pine and a decrease in the same, when galactan and protein were added to beech. Addition of xylan, lignin, and tannin to the pelletizing process, resulted in an increase in the compression work, while the addition of mannan, protein, and resins brought about a decrease in the same.

Trends very similar to the ones depicted in Figure 1, are seen in Figure 2 as well. Hence, beech had higher values for backpressure than pine. Adding lignin and tannin increased $F_{\max }$ the most for both pine and beech (Figure 2b). It is well known that extractives affect pelletability, whereof the most common effect is that extractives act as lubricating agents inside the die channels when they migrate to the pellet surface at elevated temperatures [36,37], which leads to decreased friction [38-40].
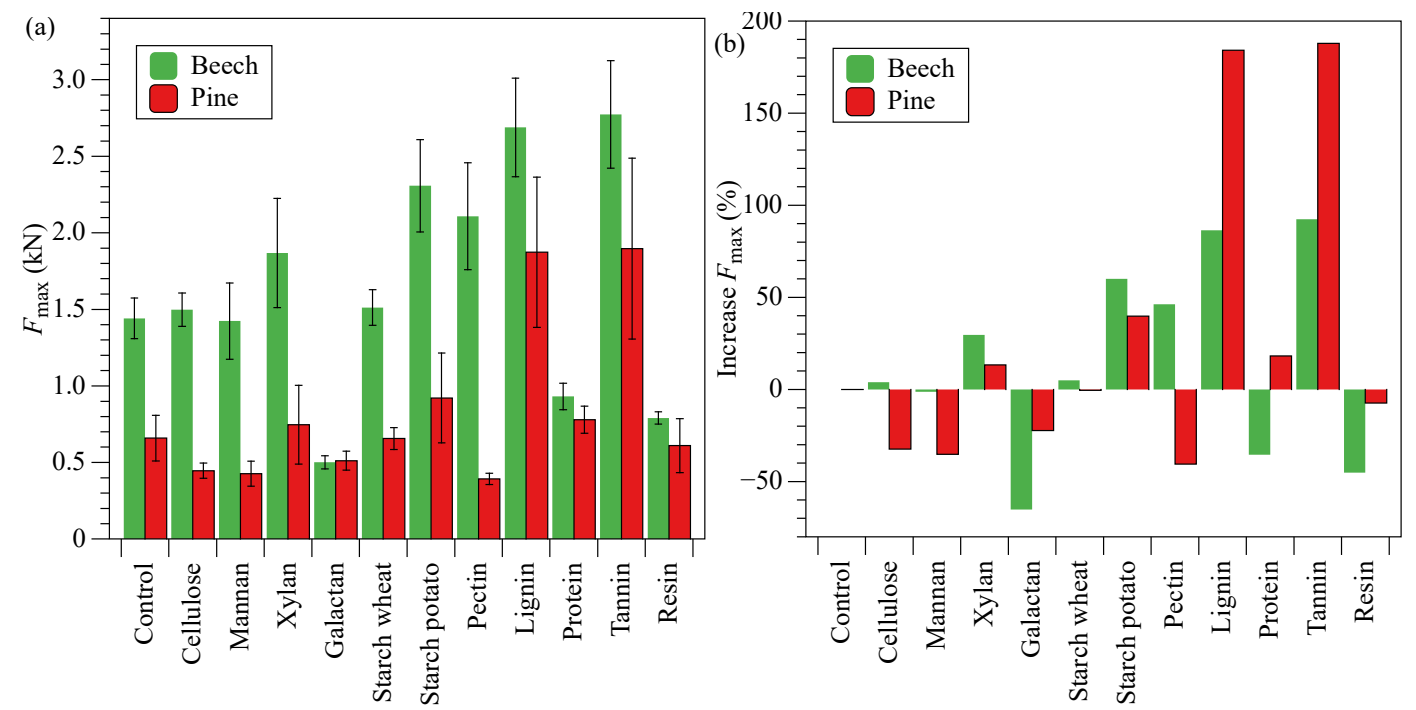

Figure 2. (a) $F_{\max }$ for all pellets $(\mathrm{kN})$ and $(\mathbf{b})$ change of $F_{\max }$ compared to pure beech and pine [\% (wb)].

In this study, two different extractives, tannin and resin, were tested. It is clear that resin acted as it did in earlier research studies and decreased the $F_{\max }$ as shown in Figure $2 \mathrm{~b}$. However, tannin countered the resin, by increasing $F_{\max }$. 


\subsection{Quality Data}

In general, the hardest pellets were produced from beech (Figure 3a) where the substances xylan, potato starch, galactan, and tannin had the most positive effect on pellet hardness. Related to pine, the substances xylan, galactan, tannin, and resin increased the hardness the most, as shown in Figure 3b. Overall, the increase in hardness was greater for pine than for beech when biomass substances were added. As shown in Figure 3b, lignin in powder form increased hardness by approximately $50 \%$ in both pine and beech. Lignin has been identified as the most important binding agent in pellets [6] based on its capacity to become fluid and create solid bridges when its glass transition temperature is reached $[9,37,41]$. However, in an earlier study by Frodeson et al. (2018), it was shown that xylan, galactan, tannin, and resin also became fluid during pelletization, and created hard pellets after cooling when they were pelletized as pure substances [23]. Waxes, similar to resin, have glass transition temperatures of approximately $40-50{ }^{\circ} \mathrm{C}$ [42] and cannot be pelletized as pure substances in ordinary pellet equipment [23]; however, as shown in Figure 3, the resin's capacity to form strong bonds was better in pine compared to beech. And as Figure 3b shows, xylan, galactan, tannin, and resin (for pine) increased the hardness much more than lignin did. It is likely, therefore, that lignin's role as the most important binding agent can be questioned. The study has also shown (Figure 3a) that when pure beech (control) with a lower lignin content compared to pine, generated harder pellets, which supports the hypothesis that lignin's role as the most important binding agent can be questioned. However, more research is needed to clarify this.
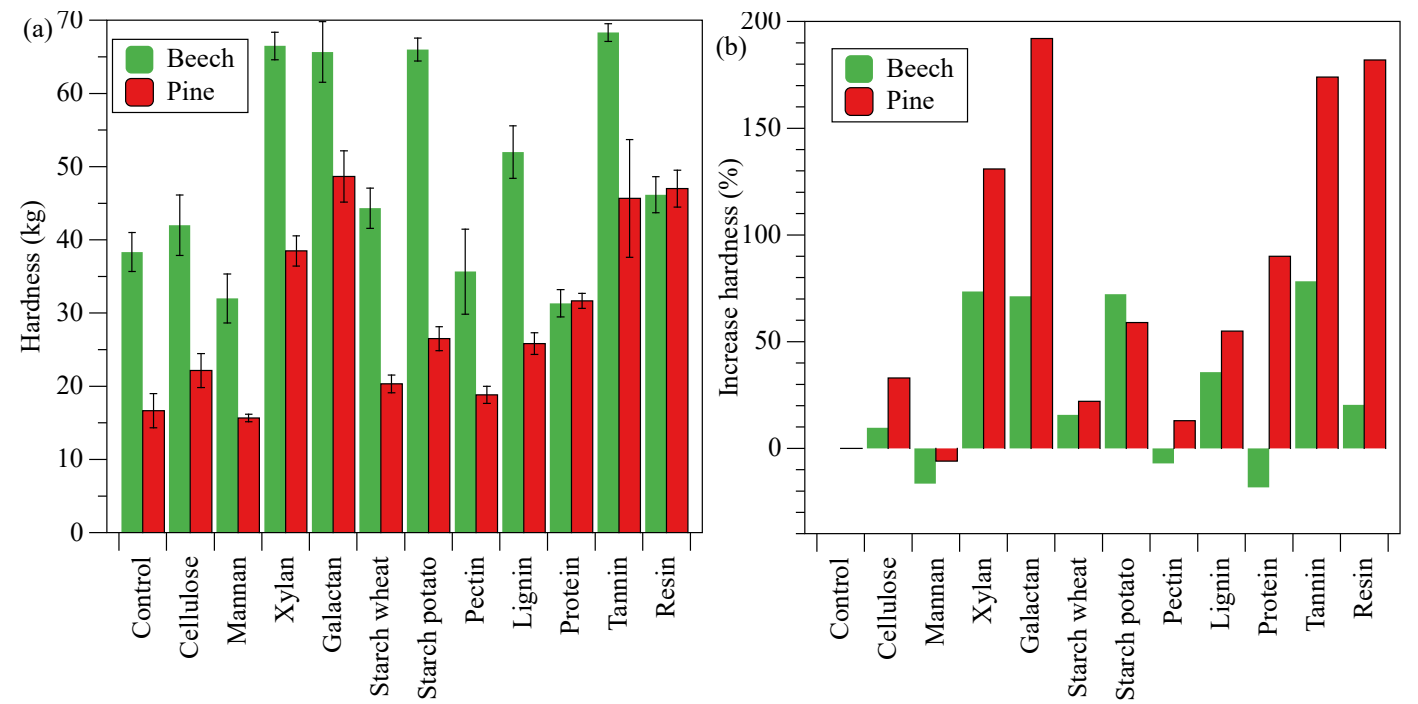

Figure 3. (a) Hardness for all pellets (kg) and (b) change of hardness compared to pure beech and pine [\% (wb)].

In Figure 3b, it can be seen that adding mannan to woods generated a weaker pellet for both beech and pine. Mannan differs from the other polysaccharides used, most likely mannan is stiffer and has a less flexible structure [28,43].

As far as wheat and potato starch are concerned, it can be seen in Figure $3 b$ that there was a difference between the effects they had on hardness as potato starch generated harder pellets than wheat starch in both beech and pine. On the contrary, Ståhl et al. (2012) showed higher durability for native wheat starch than for native potato starch [44].

However, mechanical hardness tests measure the point at which the pellets break, whereas durability tests measure the ability of pellets to withstand vibrations and collisions. This calls for more tests to verify the effect of different types of starch additives on the mechanical properties of pellets.

Regarding the compression length, i.e., the length of the pellet inside the die before the pressure is released, Figure 4a shows only small differences among all samples, and almost regardless of which substance is used, beech showed a greater springback effect 
(Figure $4 \mathrm{~b}$ ), especially when galactan, pectin, and protein were added. However, for pine, there was no springback when galactan was added.
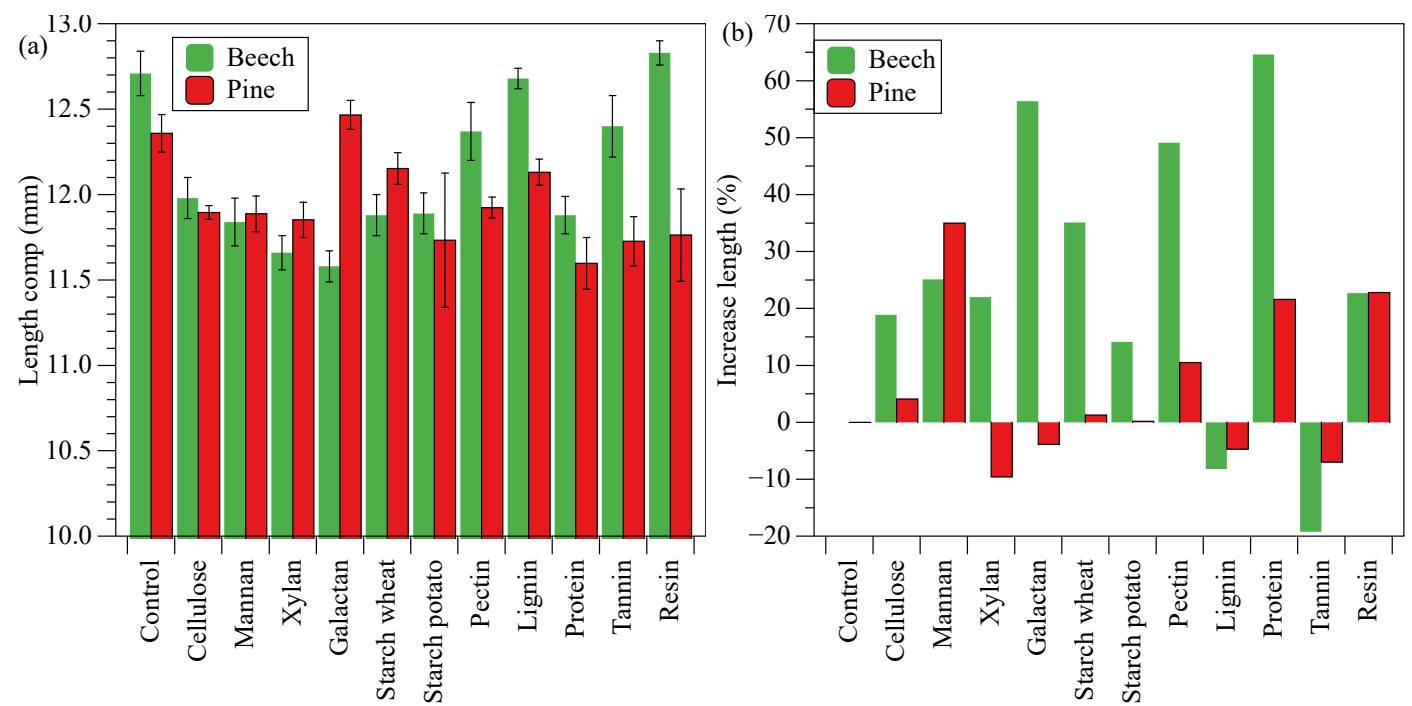

Figure 4. (a) Length for all compressed pellets $(\mathrm{mm})$ and $(\mathbf{b})$ change of length (green pellets) compared to pure beech and pine $[\%(w b)]$.

There was a clear difference between the two extractives, tannin and resin, regarding the springback effect. Tannin showed a negative springback and resin showed a relatively high springback effect (Figure $4 \mathrm{~b}$ ). The negative springback for tannin could be due to the fact that tannin has good binding properties, mainly with protein but also with polysaccharides [45].

Comparing the results in Figures 1-4 shows that for pine the substances xylan and galactan yielded interesting findings since they increased hardness without significantly affecting the compression work and $F_{\max }$, and in addition, had a low springback effect.

\subsection{Chemical Analyses}

The FT-IR spectra of the samples of beech, pine, and their blends with various substances are presented in Figures 5 and 6, respectively. The spectra depicting pure beech and pine pellets were used as controls against those of their blends containing a variety of substances in order to determine any changes of major functional groups and how these changes affected chemical bonding and pellet quality in terms of hardness. For clarity and ease of interpretation, the plots were separated into regions by a thin line. On the right-hand side of the spectra is the fingerprint region (below $1500 \mathrm{~cm}^{-1}$ ), which was not considered in the interpretation of the spectra because of its complicated and overlapping peaks; the opposite side of the spectra represents the functional group region (above $1500 \mathrm{~cm}^{-1}$ ) and is the region of interest. Due to the complexity that characterizes the FT-IR spectra of lignocellulosic biomass in general, spectral interpretation was limited to the regions in which structural modifications were most prominent and identification of the functional groups associated with these modifications.

There were obvious similarities between the spectra of the pellet samples containing substances and the beech control (Figure 5), which may be because beech was blended with $10 \%$ of different substances. However, the spectral similarities do not necessarily imply a similarity of the characteristics. A direct comparison of the spectra of the blended substances and the control sample, revealed noticeable changes around 3335, 2750, 1850, and $1650 \mathrm{~cm}^{-1}$, respectively, which are regions associated with the active bonding $\mathrm{O}-\mathrm{H}$, $\mathrm{C}-\mathrm{H}, \mathrm{C}=\mathrm{C}$ and $\mathrm{C}=\mathrm{O}$ groups [29]. The changes were noticeable through the intensity of the peaks (peak heights) representing the above-mentioned wavenumbers for all substances. While the $\mathrm{O}-\mathrm{H}$ group may have been due to the presence of phenolic hydroxyl groups linked to certain carbohydrate and polymeric constituents of cellulose, hemicellulose, 
and lignin in the samples, the $\mathrm{C}-\mathrm{H}$ and $\mathrm{C}=\mathrm{C}$ groups are connected to the methyl and methylene groups as well as the aromatics in lignin; the $\mathrm{C}=\mathrm{O}$ is owing to the carbonyl groups in hemicellulose; the $\mathrm{C}=\mathrm{O}$ could also be present due to ester groups in some of the substances, such as pectin and resin. A closer inspection of the spectra also showed (in comparison to the spectrum of the control) that the intensity of the peaks for all substances increased across the functional group region. Thus, according to Beer-Lambert's law, peak intensity (also an indicator of structural changes) is proportional to the number of functional groups. This means that an increase in peak intensity is construed to mean an increase in the concentration of functional groups. Lignin and pectin seemed to contain higher proportions of $-\mathrm{OH}$ with reduced concentration of the $\mathrm{C}-\mathrm{H}$ groups in comparison to wheat starch and galactan. The hydroxyl $(-\mathrm{OH})$ groups create cleavages of $\beta$-O-aryl ether interunit bonds [46], and their presence is an indication of the presence of intermolecular forces such as covalent and hydrogen bonding, as well as dipole-dipole interactions, which may have been activated under the process conditions of the pellet press such as temperature and compression force. Increased amounts of the $\mathrm{C}=\mathrm{O}$ and $\mathrm{C}=\mathrm{C}$ groups introduce more intermolecular forces of attraction because of the polar nature of these groups, particularly the $\mathrm{C}=\mathrm{O}$ group [29]. Therefore, a combination of the attraction forces creates stronger bond energies and bond strength; furthermore, the quality of biomass pellets, in terms of hardness, is a function of the type and strength of attraction forces holding particles together $[9,29]$. Nonetheless, because of too much peak overlap and the complex nature of the infrared (IR) spectra of lignocellulosic biomass, direct spectra interpretation in relation to why some substances, such as tannin, xylan, and galactan, gave harder pellets and mannan resulted in weaker pellets according to the hardness plot in Figure 3 could not be immediately determined and constitutes a major limitation of this analysis. Perhaps special software that would allow for spectral peak deconvolution is needed to overcome this challenge.

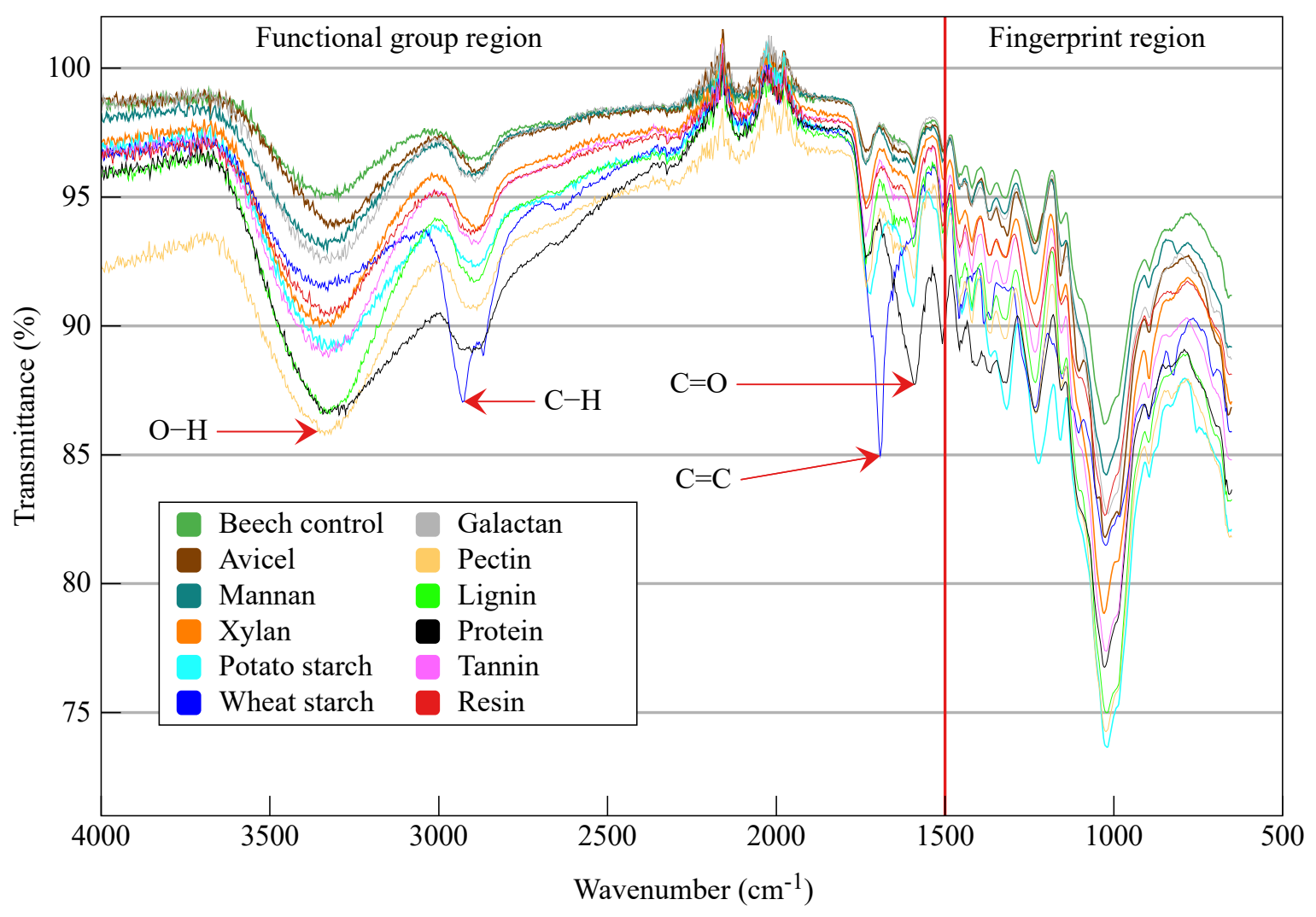

Figure 5. FT-IR spectra results from beech pellets (control and when added with eleven different substances). 


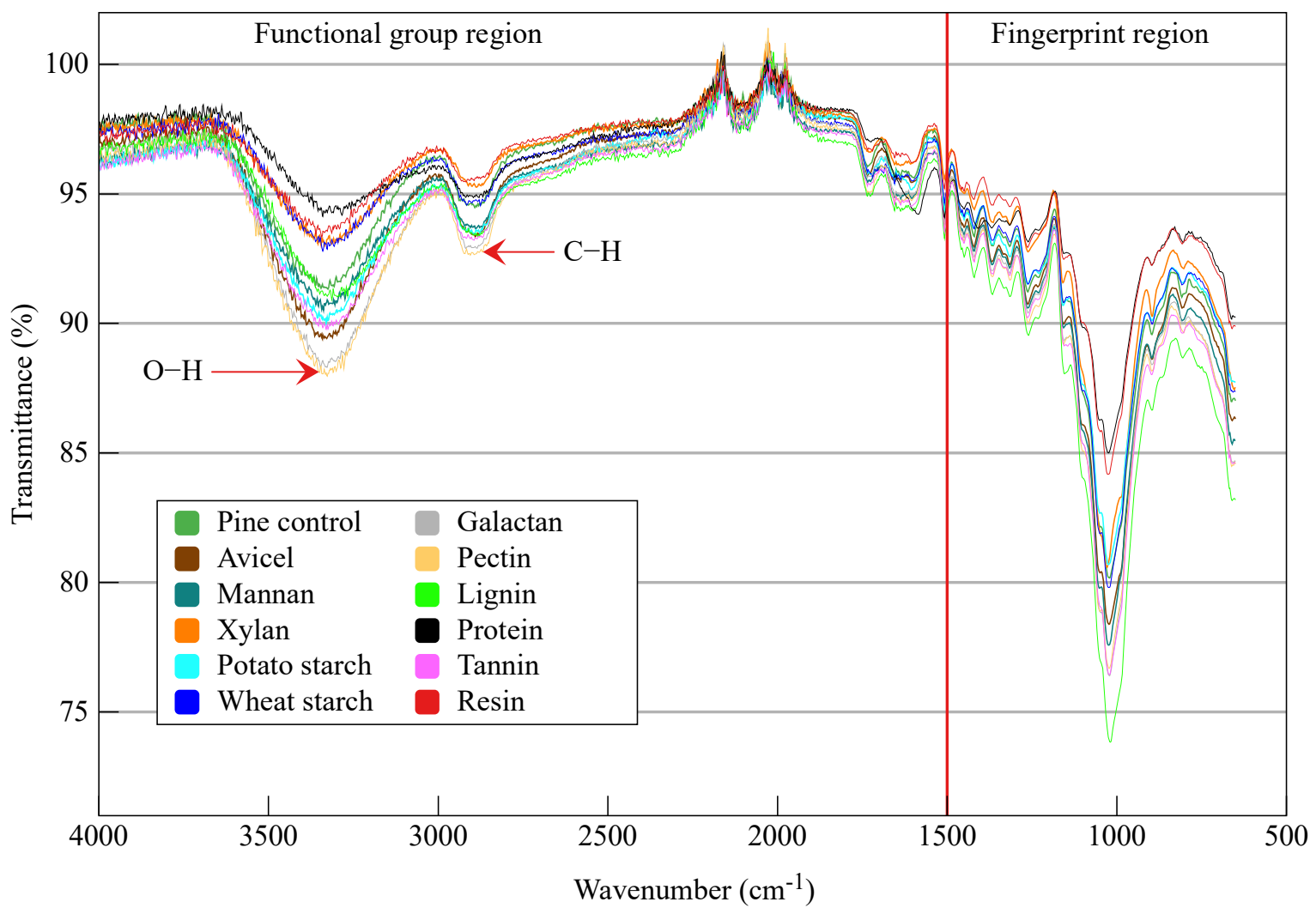

Figure 6. FT-IR spectra results from pine pellets (control and when added with eleven different substances).

There were also spectral similarities between pine control and its added substances presented in Figure 6. The reason for these similarities is the same as that given for the previous samples (beech control and its added substances). The spectra were characterized by two peaks in regions 3335 and $2750 \mathrm{~cm}^{-1}$, which are linked to the $\mathrm{O}-\mathrm{H}$ and $\mathrm{C}-\mathrm{H}$ groups. It is worth mentioning that biomass moisture content can increase the amount of $\mathrm{O}-\mathrm{H}$ groups and facilitate interparticle hydrogen bonding as well as increase the availability of bonding sites [40].

In comparison to the pine control, only three of the substances (wheat starch, mannan, and protein) showed reduced peak intensity in terms of the height of the peaks around the $\mathrm{O}-\mathrm{H}$ region, and in the $\mathrm{C}-\mathrm{H}$ region, five of the substances (pectin, galactan, tannin, lignin, and resin) displayed increased peak intensity, which is an indication of a higher concentration of the $\mathrm{C}-\mathrm{H}$ groups. It should be noted that there is a relationship between peak intensity and the concentration of functional groups (Beer-Lambert's law), as previously explained. Once again, why some substances produced harder pellets than others could not be established from the spectral information for reasons given previously. However, there seemed to be clear differences between the IR spectra of the Pine pellets in Figure 6 and those of the beech pellets previously presented in Figure 5 . The spectra of both controls (pine and beech pellets) with the same types and amounts of added substances typically differed around the functional group region, which was noticeable in the number of peaks (only two peaks for Figure 4) and the intensity of the peaks in terms of height. The two peaks were displayed at around 3335 and $2750 \mathrm{~cm}^{-1}$, which, as indicated in Figure 6, were linked to the $\mathrm{O}-\mathrm{H}$ and $\mathrm{C}-\mathrm{H}$ groups, respectively. Moreover, the intensity of the peak depicting the $\mathrm{C}-\mathrm{H}$ group in Figure 6 was lower than those for beech and its added substances in the previous figure, coupled with the fact that no peaks could be observed in the region associated with the $\mathrm{C}=\mathrm{O}$ and the $\mathrm{C}=\mathrm{C}$ groups $\left(1850\right.$ and $\left.1650 \mathrm{~cm}^{-1}\right)$ as in the case of Figure 5, which is an indication that not much interaction took place upon the addition of $10 \%$ of various substances to the pine pellets. This simply means that the pine control pellet sample was less susceptible to chemical changes induced by the addition 
of substances and less likely to form pellets with increased hardness than beech, which agreed with the hardness data of the beech and pine pellets presented in Figure 3.

The SEM images of pellets made from beech, pine, and their corresponding blends with different substances are presented in Figures 7 and 8, respectively. As in the case of the previous FT-IR data, images of the beech and pine control were used as the basis for comparison with the images of their corresponding substance blends. The images clearly show some morphological similarities in terms of how particles are tightly packed and entangled, which is an indication of the production of pellets with increased density.

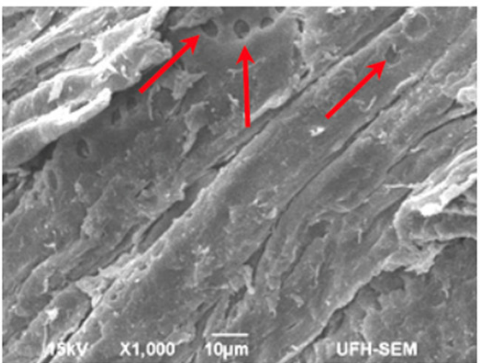

Beech control
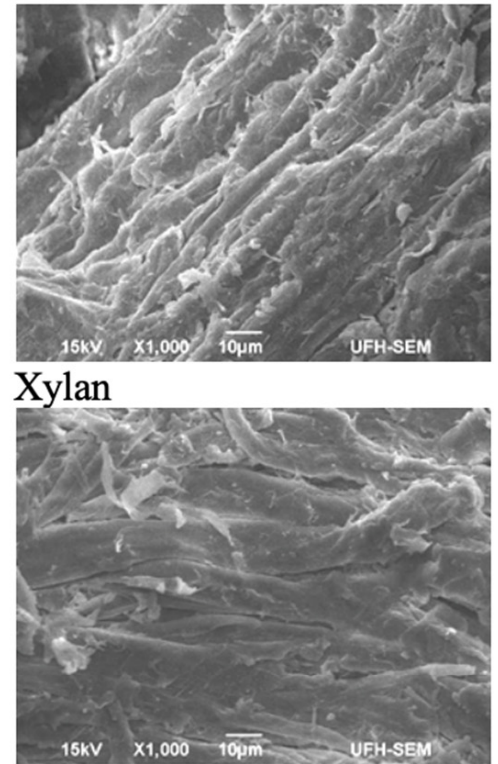

Galactan

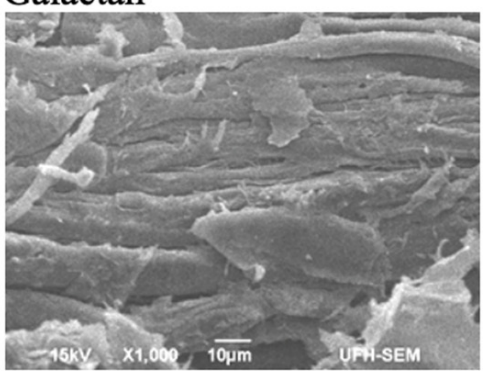

Protein

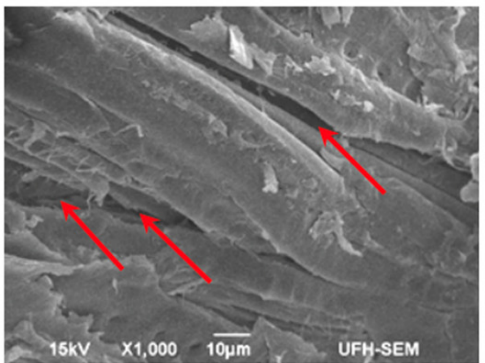

Avicel

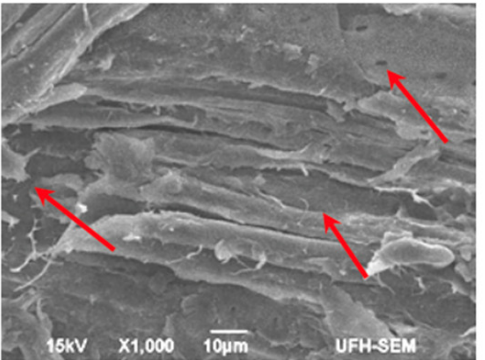

Wheat starch

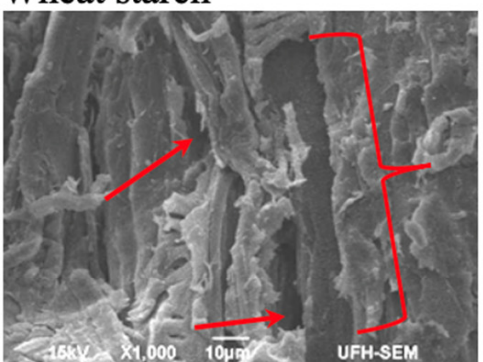

Pectin

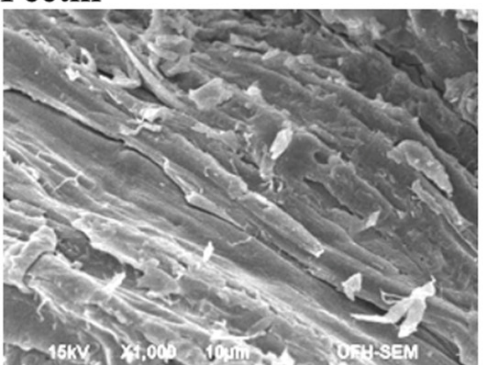

Tannin

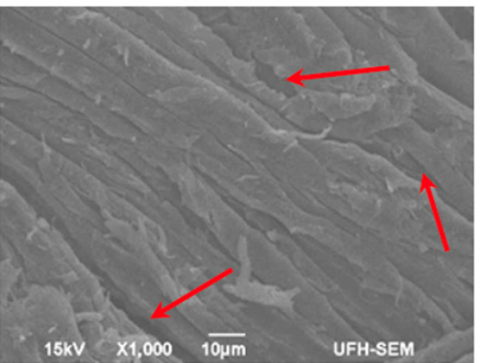

Mannan

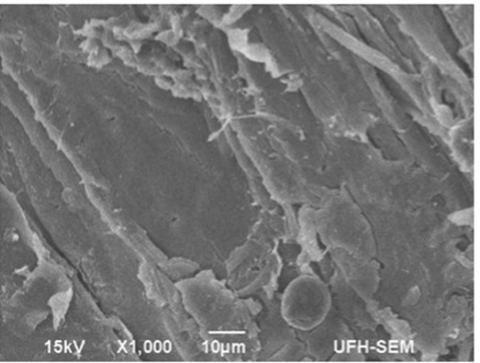

Potato starch

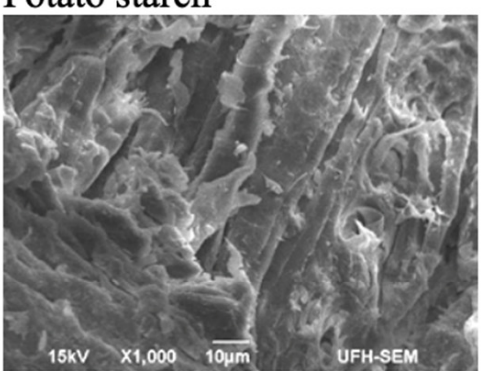

Lignin

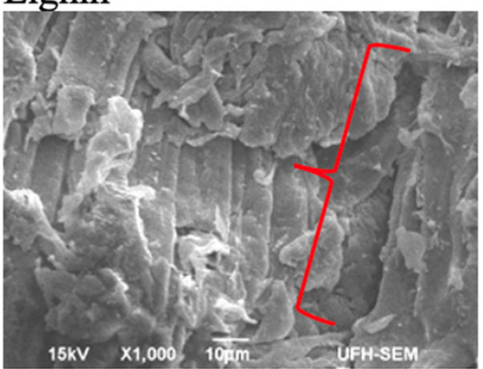

Resin

Figure 7. The SEM images of the beech pellets (control and when added with eleven different substances). 


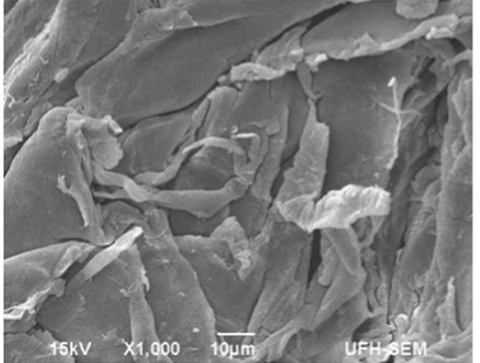

Pine Control

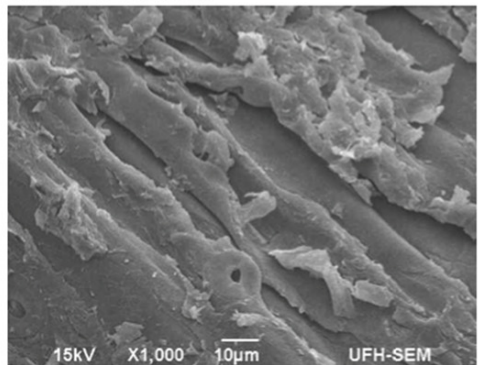

Xylan

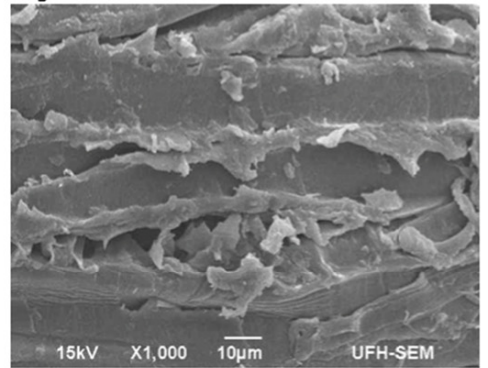

Galactan

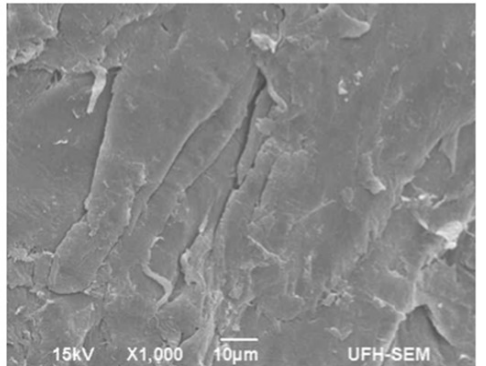

Protein

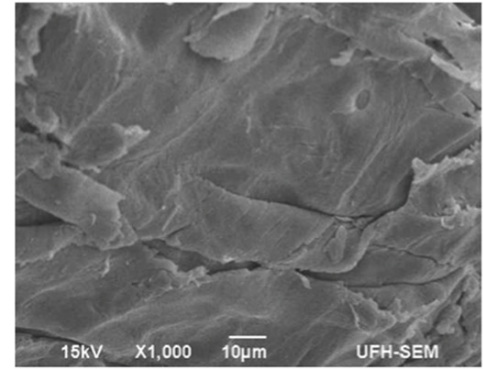

Avicel

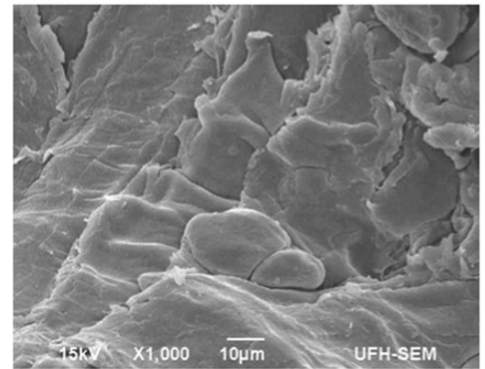

Wheat starch

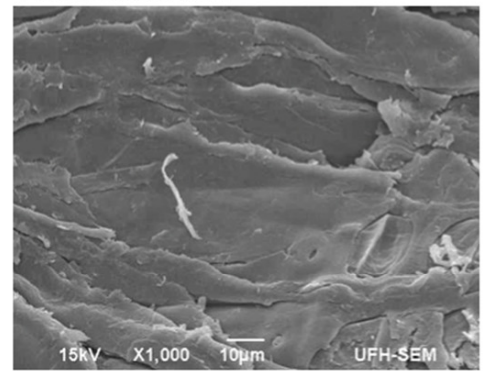

Pectin

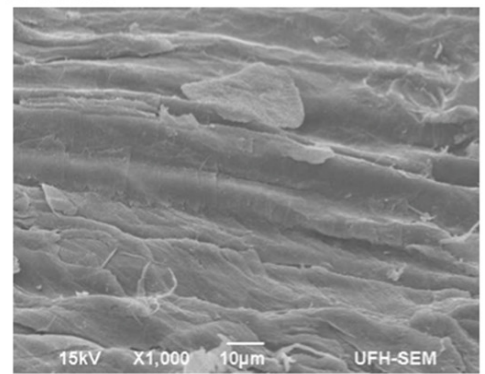

Tannin

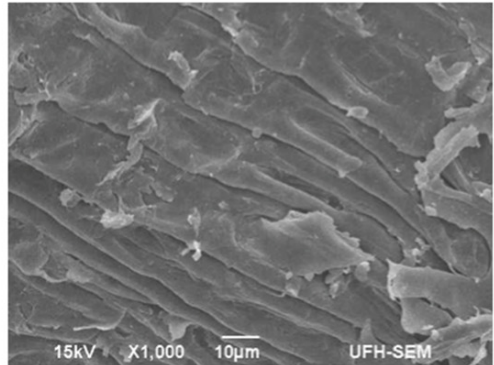

Mannan

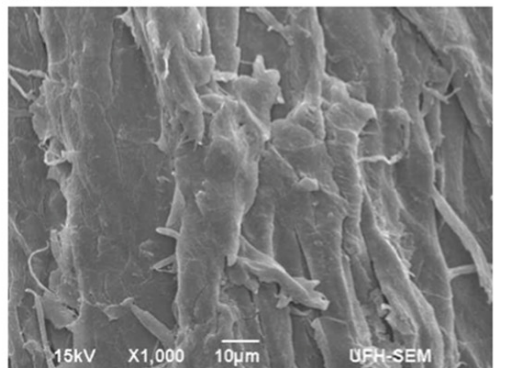

Potato starch

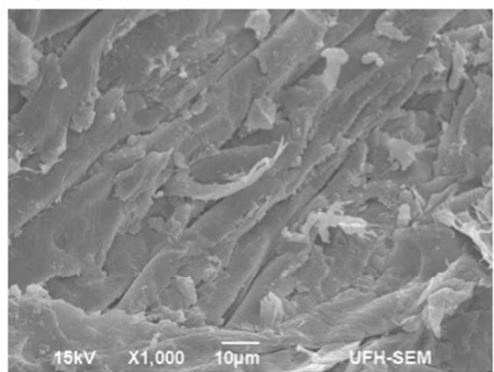

\section{Lignin}

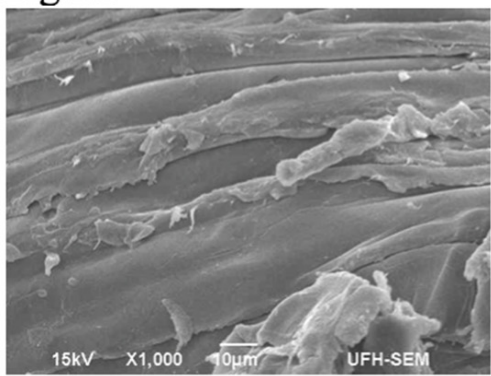

Resin

Figure 8. The SEM images of all pine pellets (control and when added with eleven different substances).

However, the density of the pellets varied according to the bonding between particles and the type of substance. This was further explained in accordance with the SEM images of the pellets. To make interpretation less complicated, a few important pellet samples were considered.

Generally, in terms of surface morphology, significant differences were noted when the images of the substances were compared with the image of the beech control. There seemed to be differences in the surface appearance of the pellet samples, which were probably caused by compositional differences and the processing conditions of the pellet press. However, the images reveal the extent of adhesion/bonding between particles, which varied with the type of substances, perhaps due to dissimilarities in the type and number of moieties (functional groups) of the biopolymeric constituents of the samples and may account for the varying degrees of hardness and springback behavior of the pellets presented in a previous section (Figures 3 and 4, respectively). This may also be the reason why there was a disparity in energy consumption and frictional force during the 
pelletizing process, according to the data in Figures 1 and 2, respectively. This is because biopolymeric constituents respond differently under the processing conditions of the pellet press $[35,47]$. These findings are supported by the findings of Nielson et al. (2010) and Stelte et al. (2012) [40,48], who showed that biomass polymeric components on the pellet surface strongly influence not only the appearance and unit density of pellets but also their springback behavior, energy consumption, and the frictional force of the pelletizing process. For instance, the surface morphology of the beech control is quite rough with visible spherical pores that are almost invisible in most of the substances. The visible pores were considered as areas of cohesive failure that may have been created by a lack of biopolymer interpenetration or a lack of particle inter-diffusion attributed to pressing at high temperatures. While the images of pellets with substances such as Avicel, wheat starch, pectin, and resin reveal large gaps between particles (identified by the arrows in the images) that reflect weak bonding, other substances show particles that are strongly bonded to each other; these include xylan, potato starch, galactan, lignin, protein, and tannin. This is an indication of structural differences supported by the FT-IR data presented in a previous section and could also explain the variation in the quality of the pellets in terms of hardness, considering the data in Figure 3. However, why specific pellet samples such as xylan, galactan, and tannin gave harder pellets and mannan gave softer pellets could not be immediately ascertained from this analysis. A possible explanation for the gaps seen between particles in the images of the pellet samples mentioned above is that although substances may function to improve bonding between particles, this depends on the type and composition of the substance. Therefore, it is likely that the substances that showed weaker inter-particle bonding may contain polyester substances that can limit areas of interaction where strong bonding is likely to occur. These polyester substances may act as a shield against the polymer chains of cellulose, hemicellulose, and lignin by preventing participation in bond formation and consequently limiting particle-to-particle bonding to weak van der Waals interactions and poor interlocking of fibers [40]. To prove this theory, however, a compositional analysis of beech pellets and the substances used in this study may be necessary.

The SEM images of pine pellet control and its corresponding blends with various substances also revealed a compact surface morphology and particle entanglement across all images (Figure 8).

The surface morphology of the pine control also appeared coarse with detached particles that were randomly distributed, an indication of lower energy consumption, and perhaps a result of van der Waals attraction forces between particles. The detached particles from the surface of the pine control may have been caused by the springback effect during pelletization or may be a result of how the pellet samples were manually cut before analysis. In contrast, varying degrees of surface coarseness could be noted from the images of the blends with particles more tightly held together. This change in surface morphology is obviously due to reinforced biopolymeric constituents facilitated by the substances and process conditions. While the images of some of the substances, such as Avicel (cellulose powder) and proteins, revealed fairly smooth surfaces, the images of other substances, such as mannan, clearly showed solid bridges that were thought to be evidence of the presence of linear chains of 1.4-linked $\beta$-D-mannopyranosyl residues. The same is true for xylan whose image revealed a lump around the solid bridges thought to be residues of D-xylopyranose, which is a structurally fortified component with significant mitogenic and comitogenic activities [49]. The particles on the surface of the SEM image of galactan appeared as cell structures that were considered as tight polysaccharide networks that may have been made prominent by the processing conditions of the pellet press. Tannin also revealed thread-like linear particles that could be construed to also mean the presence of solid bridges with an artefact on the surface. The artefact was considered a potential and dynamic precursor structure that reflects the hidden tendencies of micromolecules. Again, the morphological features of the pellet samples revealed key structural differences that could account for the variations in not only the hardness and springback behavior of the 
pellets, but also their energy consumption and the frictional force of the pelletizing process presented in previous sections.

\section{Concluding Remarks}

The purpose of this study was to gain a better understanding of how the naturallyoccurring substances in biomasses affect pelletizing properties of beech and pine. Eleven different substances were considered in the analysis and pelletized in an SPP press with as similar physical properties as possible between the control tests and those where the various substances were added.

It can be concluded that, regardless of the substances used, beech acquires more compression energy, has greater springback effect, and yields harder pellets than pine. However, neither the FT-IR spectra nor the SEM images could prove this.

A conclusion is that more research is needed to clarify extractives substances' role during densification. As shown in the results, the extractives, tannin, and resin showed a clear difference regarding the $F_{\max }$ and the springback effect. Tannin showed a negative springback and increased the friction within the die while resin showed a relatively high springback effect and lubricating behavior within the die.

The FT-IR data could not provide a clear explanation for the variation in quality in terms of hardness and the springback behavior of each pellet. This was because no direct relationship could be established between the identified functional groups and the elastic energy stored in the pellet samples. However, an alternative analysis involving molecular dynamics simulation could help to establish such a relationship and subsequently be used to understand the springback effect of biomaterials during pelletization. Additionally, spectral peak deconvolution with special software is recommended to overcome the challenges of peak overlap from FT-IR analysis and to ensure less complicated spectral interpretations.

Another conclusion is that biomass residues, rich with xylan and galactan, should be tested as a mix in pellet production to explore its potential to increase pellet quality without affecting the production process. When these substances, xylan and galactan, were added to pine, the pellet quality in form of hardness increased without significantly affecting the compression work and $F_{\max }$, these pellets also had a low springback effect. For xylan, galactan, and tannin, SEM images showed particles that are strongly bonded to each other while SEM images of pellets with substances such as Avicel (cellulose powder), wheat starch, pectin, and resin revealed large gaps between particles.

As a final remark, adding biomass residues, rich with xylan and galactan, could mean that raw materials that are difficult to pelletize can be used as raw material for pellet producers, which could broaden the raw material base.

Author Contributions: Conceptualization, S.F. and J.B.; methodology, S.F., A.I.A. and R.L.K.N.; investigation, R.L.K.N. and E.B.A.; data curation; S.F., A.I.A. and J.B.; formal analysis; S.F., A.I.A., J.B. and G.H.; writing-original draft, S.F., A.I.A., M.S. and J.B.; writing-review and editing R.L.K.N., G.H. and E.B.A.; funding acquisition; S.F. All authors have read and agreed to the published version of the manuscript.

Funding: This work was supported by the Swedish Agency for Economic and Regional Growth through the FOSBE project (grant number 20201239) and the Faculty of Health, Science and Technology at Karlstad University, Sweden.

Acknowledgments: Many thanks to Lars Pettersson at Karlstad University for laboratory support.

Conflicts of Interest: The authors declare no conflict of interest.

\section{References}

1. European Commission. Innovating for Sustainable Growth: A Bioeconomy for Europe; European Commission: Brussels, Belgium, 2012.

2. Tumuluru, J.S.; Wright, C.T.; Hess, J.R.; Kenney, K.L. A review of biomass densification systems to develop uniform feedstock commodities for bioenergy application. Biofuels Bioprod. Biorefin. 2011, 5, 683-707. [CrossRef]

3. Walker, S.; Strauss, W. Global Wood Pellet Markets Outlook. 2019. Available online: https://www.canadianbiomassmagazine.ca/ 2019-wood-pellet-markets-outlook-7190/ (accessed on 8 October 2020). 
4. Brandeis, C.; Abt, K.L. Roundwood use by Southern wood pellet mills: Findings from timber product output mill surveys. J. For. 2019, 117, 427-434. [CrossRef]

5. Kaliyan, N.; Vance Morey, R. Factors affecting strength and durability of densified biomass products. Biomass Bioenergy 2009, 33, 337-359. [CrossRef]

6. Whittaker, C.; Shield, I. Factors affecting wood, energy grass and straw pellet durability-A review. Renew. Sustain. Energy Rev. 2017, 71, 1-11. [CrossRef]

7. Rumpf, H. The strength of granules and agglomerate. In Proceedings of the First International Symposium on Agglomeration, Philadelphia, Philadelphia, PA, USA, 12-14 April 1961; John Wiley and Sons: London, UK, 1962; pp. 379-418.

8. Mani, S.; Tabil, L.; Sokhansanj, S. Compaction of biomass grinds-an overview of compaction of biomass grinds. Powder Handl. Process. 2003, 15, 160-168.

9. Kaliyan, N.; Morey, R.V. Natural binders and solid bridge type binding mechanisms in briquettes and pellets made from corn stover and switchgrass. Bioresour. Technol. 2010, 101, 1082-1090. [CrossRef]

10. Stelte, W.; Sanadi, A.R.; Shang, L.; Holm, J.K.; Ahrenfeldt, J.; Henriksen, U.B. Recent developments in biomass pelletization-A review. BioResources 2012, 7, 4451-4490. [CrossRef]

11. Poddar, S.; Kamruzzaman, M.; Sujan, S.M.A.; Hossain, M.; Jamal, M.S.; Gafur, M.A.; Khanam, M. Effect of compression pressure on lignocellulosic biomass pellet to improve fuel properties: Higher heating value. Fuel 2014, 131, 43-48. [CrossRef]

12. Mani, S.; Tabil, L.G.; Sokhansanj, S. Effects of compressive force, particle size and moisture content on mechanical properties of biomass pellets from grasses. Biomass Bioenergy 2006, 30, 648-654. [CrossRef]

13. Ramírez-Gómez, Á. Research needs on biomass characterization to prevent handling problems and hazards in industry. Part. Sci. Technol. 2016, 34, 432-441. [CrossRef]

14. Holm, J.K.; Henriksen, U.B.; Hustad, J.E.; Sørensen, L.H. Toward an understanding of controlling parameters in softwood and hardwood pellets production. Energy Fuels 2006, 20, 2686-2694. [CrossRef]

15. Anukam, A.; Berghel, J.; Henrikson, G.; Frodeson, S.; Ståhl, M. A review of the mechanism of bonding in densified biomass pellets. Renew. Sustain. Energy Rev. 2021, 148, 111249. [CrossRef]

16. Picchio, R.; Latterini, F.; Venanzi, R.; Stefanoni, W.; Suardi, A.; Tocci, D.; Pari, L. Pellet production from woody and non-woody feedstocks: A review on biomass quality evaluation. Energies 2020, 13, 2937. [CrossRef]

17. Tarasov, D.; Shahi, C.; Leitch, M. Effect of additives on wood pellet physical and thermal characteristics: A review. ISRN For. 2013, 2013, 876939. [CrossRef]

18. Kuokkanen, M.J.; Vilppo, T.; Kuokkanen, T.; Stoor, T.; Niinimäki, J. Additives in wood pellet production-A pilot-scale study of binding agent usage. BioResources 2011, 6, 4331-4355.

19. Larsson, S.; Lockneus, O.; Xiong, S.; Samuelsson, R. Cassava stem powder as an additive in biomass fuel pellet production. Energy Fuels 2015, 29, 5902-5908. [CrossRef]

20. Berghel, J.; Frodeson, S.; Granström, K.; Renström, R.; Ståhl, M.; Nordgren, D.; Tomani, P. The effects of kraft lignin additives on wood fuel pellet quality, energy use and shelf life. Fuel Process. Technol. 2013, 112, 64-69. [CrossRef]

21. Samuelsson, R.; Finell, M.; Arshadi, M.; Hedman, B.; Subirana, J. Inblandning av Stärkelse och Lignosulfonat $i$ Pellets vid Bioenergi $i$ Luleå AB; Department of Forest Biomaterials and Technology: Uppsala, Sweden, 2014; Volume 29.

22. Khlifi, S.; Lajili, M.; Belghith, S.; Mezlini, S.; Tabet, F.; Jeguirim, M. Briquettes production from olive mill waste under optimal temperature and pressure conditions: Physico-chemical and mechanical characterizations. Energies 2020, 13, 1214. [CrossRef]

23. Frodeson, S.; Henriksson, G.; Berghel, J. Pelletizing pure biomass substances to investigate the mechanical properties and bonding mechanisms. BioResources 2018, 13, 1202-1222. [CrossRef]

24. Frodeson, S.; Henriksson, G.; Berghel, J. Effects of moisture content during densification of biomass pellets, focusing on polysaccharide substances. Biomass Bioenergy 2019, 122, 322-330. [CrossRef]

25. Frodeson, S.; Lindén, P.; Henriksson, G.; Berghel, J. Compression of biomass substances-A study on springback effects and color formation in pellet manufacture. Appl. Sci. 2019, 9, 4302. [CrossRef]

26. Frodeson, S. Towards understanding the Pelletizing Process of Biomass: Perspectives on Energy Efficiency and Pelletability of Pure Substances; Karlstads universitet: Karlstad, Sweden, 2019.

27. Larsson, S.; Agar, D.; Rudolfsson, M.; Da Silva Perez, D.; Campargue, M.; Kalen, G.; Thyrel, M. Using macromolecular composition to predict optimal process settings in ring-die biomass pellet production. Fuel 2021, 283, 9. [CrossRef]

28. Ek, M.; Gellerstedt, G.; Henriksson, G. Wood Chemistry and Biotechnology; Walter de Gruyter: Berlin, Germany, $2009 ;$ Volume 1.

29. Anukam, A.I.; Berghel, J.; Frodeson, S.; Famewo, E.B.; Nyamukamba, P. Characterization of pure and blended pellets made from Norway spruce and Pea starch: A comparative study of bonding mechanism relevant to quality. Energies 2019, $12,4415$. [CrossRef]

30. Kudahettige-Nilsson, R.L.; Ullsten, H.; Henriksson, G. Plastic composites made from glycerol, citric acid, and forest components. BioResources 2018, 13, 6600-6612. [CrossRef]

31. Bi, R.; Berglund, J.; Vilaplana, F.; McKee, L.S.; Henriksson, G. The degree of acetylation affects the microbial degradability of mannans. Polym. Degrad. Stab. 2016, 133, 36-46. [CrossRef]

32. Abbaszadeh, A.; MacNaughtan, W.; Sworn, G.; Foster, T.J. New insights into xanthan synergistic interactions with konjac glucomannan: A novel interaction mechanism proposal. Carbohydr. Polym. 2016, 144, 168-177. [CrossRef] [PubMed] 
33. Kaliyan, N.; Morey, R.V. Constitutive model for densification of corn stover and switchgrass. Biosyst. Eng. 2009, 104, 47-63. [CrossRef]

34. Dhamodaran, A.; Afzal, M.T. Compression and springback properties of hardwood and softwood pellets. BioResources 2012, 7, 4362-4376.

35. Anukam, A.I.; Berghel, J.; Famewo, E.B.; Frodeson, S. Improving the understanding of the bonding mechanism of primary components of biomass pellets through the use of advanced analytical instruments. J. Wood Chem. Technol. 2020, 40, 15-32. [CrossRef]

36. Castellano, J.M.; Gómez, M.; Fernández, M.; Esteban, L.S.; Carrasco, J.E. Study on the effects of raw materials composition and pelletization conditions on the quality and properties of pellets obtained from different woody and non woody biomasses. Fuel 2015, 139, 629-636. [CrossRef]

37. Stelte, W.; Holm, J.K.; Sanadi, A.R.; Barsberg, S.; Ahrenfeldt, J.; Henriksen, U.B. A study of bonding and failure mechanisms in fuel pellets from different biomass resources. Biomass Bioenergy 2011, 35, 910-918. [CrossRef]

38. Samuelsson, R.; Thyrel, M.; Sjöström, M.; Lestander, T.A. Effect of biomaterial characteristics on pelletizing properties and biofuel pellet quality. Fuel Process. Technol. 2009, 90, 1129-1134. [CrossRef]

39. Filbakk, T.; Skjevrak, G.; Høibø, O.; Dibdiakova, J.; Jirjis, R. The influence of storage and drying methods for Scots pine raw material on mechanical pellet properties and production parameters. Fuel Process. Technol. 2011, 92, 871-878. [CrossRef]

40. Stelte, W.; Clemons, C.; Holm, J.K.; Ahrenfeldt, J.; Henriksen, U.B.; Sanadi, A.R. Fuel pellets from wheat straw: The effect of lignin glass transition and surface waxes on pelletizing properties. Bioenergy Res. 2012, 5, 450-458. [CrossRef]

41. Wilson, T.O. Factors Affecting Wood Pellet Durability; The Pennsylvania State University: State College, PA, USA, 2010.

42. Stelte, W.; Clemons, C.; Holm, J.K.; Ahrenfeldt, J.; Henriksen, U.B.; Sanadi, A.R. Thermal transitions of the amorphous polymers in wheat straw. Ind. Crops Prod. 2011, 34, 1053-1056. [CrossRef]

43. Berglund, J.; Angles d'Ortoli, T.; Vilaplana, F.; Widmalm, G.; Bergenstråhle-Wohlert, M.; Lawoko, M.; Henriksson, G.; Lindström, M.; Wohlert, J. A molecular dynamics study of the effect of glycosidic linkage type in the hemicellulose backbone on the molecular chain flexibility. Plant J. 2016, 88, 56-70. [CrossRef] [PubMed]

44. Ståhl, M.; Berghel, J.; Frodeson, S.; Granström, K.; Renström, R. Effects on pellet properties and energy use when starch is added in the wood-fuel pelletizing process. Energy Fuels 2012, 26, 1937-1945. [CrossRef]

45. Gemechu, F.G. Embracing nutritional qualities, biological activities and technological properties of coffee byproducts in functional food formulation. Trends Food Sci. Technol. 2020, 104, 235-261. [CrossRef]

46. Nuopponen, M.; Vuorinen, T.; Jämsä, S.; Viitaniemi, P. Thermal modifications in softwood studied by FT-IR and UV resonance Raman spectroscopies. J. Wood Chem. Technol. 2005, 24, 13-26. [CrossRef]

47. Stelte, W.; Holm, J.K.; Sanadi, A.R.; Barsberg, S.; Ahrenfeldt, J.; Henriksen, U.B. Fuel pellets from biomass: The importance of the pelletizing pressure and its dependency on the processing conditions. Fuel 2011, 90, 3285-3290. [CrossRef]

48. Nielsen, N.P.K.; Gardner, D.J.; Felby, C. Effect of extractives and storage on the pelletizing process of sawdust. Fuel 2010, 89, 94-98. [CrossRef]

49. Ebringerová, A.; Hromadkova, Z.; Hřibalová, V. Structure and mitogenic activities of corn cob heteroxylans. Int. J. Biol. Macromol. 1995, 17, 327-331. [CrossRef] 